\title{
New Positive Type Photosensitive Polyimide: Hyperbranched Poly (Ether imide) with Diazonaphthoquinone
}

\author{
Masaki Okazaki, Yuji Shibasaki, Mitsuru Ueda, ${ }^{\dagger}$ \\ Department of Organic and Polymeric materials, Tokyo Institute of Technology, Ookayama 2-12-1, \\ Meguro-ku, Tokyo 152-8552, JAPAN
}

\begin{abstract}
A positive working photosensitive polyimide based on hyperbranched poly (ether imide) (H-PEI) and 2,3,4-tris[1-oxo-2-diazonaphthoquinone-5-sulfonyloxy] benzophenone (D5SB) as a photoreactive compound has been developed. H-PEI was prepared by polycondensation of 3,5-di-tert-butyldimethylsilyloxyphenyl-4-fluorophthalimide, followed by deprotection of tert-butyldimethylsilyl group with KF-HBr. The H-PEI has an excellent transparency to UV light. The photosensitive polyimide containing $30 \mathrm{wt} \%$ of DSSB showed a sensitivity of $120 \mathrm{~mJ} \cdot \mathrm{cm}^{-2}$ and a contrast of 2.8 when it was exposed to $365 \mathrm{~nm}$ light followed by developing with a $2.38 \%$ aqueous tetramethylammonium hydroxide (TMAH) solution at room temperature.
\end{abstract}

\section{Keywords: hyperbranched polymer, polyimide, dissolution inhibitor, alkaline soluble}

\section{Introduction}

Photosensitive polyimides (PSPIs) are widely used as protection and insulation layers in semiconductor manufacturing because the number of processing steps is reduced by avoiding the use of classical photoresist in the microlithograpy. So far various negative and positive type PSPIs were reported.[1,2] For example, most of the negative type PSPIs are prepared from poly(amic acid)s containing photopolymerization sites such as acryloyl groups on the polymer backbone.[3] On the other hand, the positive type PSPIs consist of poly (amic acid)s and dissolution inhibitors such as $o$-diazonaphthoquinone (DNQ), 1,4-dihydropyridine derivatives, $[4,5]$ and $o$-nitrobenzyl esters of polyamic acid.[6] However, these resist systems require high thermal treatment for the imidization after development, which is not suitable for semiconductor manufacturing. Therefore, positive type alkaline developable PSPIs based on poly (hydroxyimide)s and DNQ have been reported.[7]

Generally, these polyimide matrixes show low solubility in common organic solvents and have a problem to introduce alkaline developable functional groups.

Hyperbranched polymers have been attracting great interest for their unique properties such as intrinsic globular structure, low viscosity, high solubility and large number of terminal functional groups. While there have been many reports on the synthesis and characterization of hyperbranched polymers, little work has been done for testing potential applications. Thus, we have been interested in hyperbranched poly (ether imide)s which have imide back bones and many phenolic hydroxyl groups on terminal units.

This paper describes a novel application of hyperbranched polymers as a photosensitive polymer matrix, that is, a positive type alkaline developable PSPI system based on hyperbranched poly (ether imide) and DNQ as a dissolution inhibitor will be reported.

\section{Experimental}

\subsection{Materials}

All materials and solvents were commercially available and used as received. 

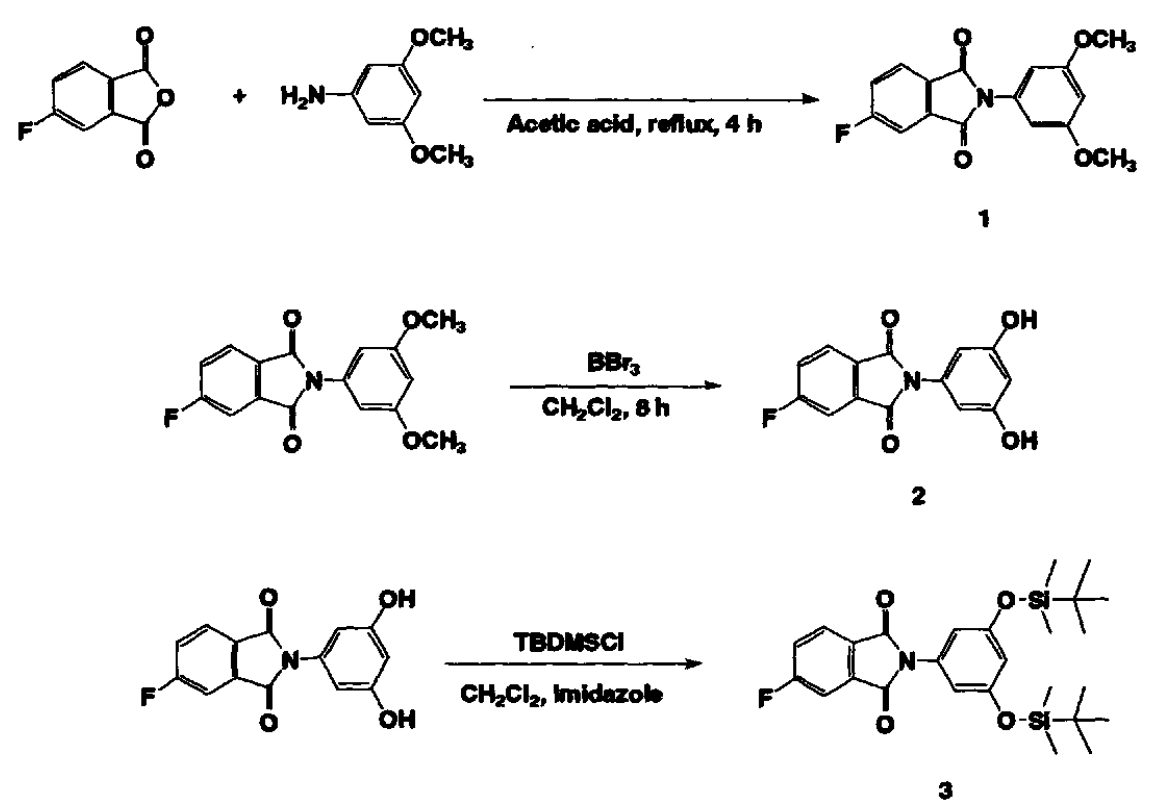

Scheme 1. Monomer Synthesis
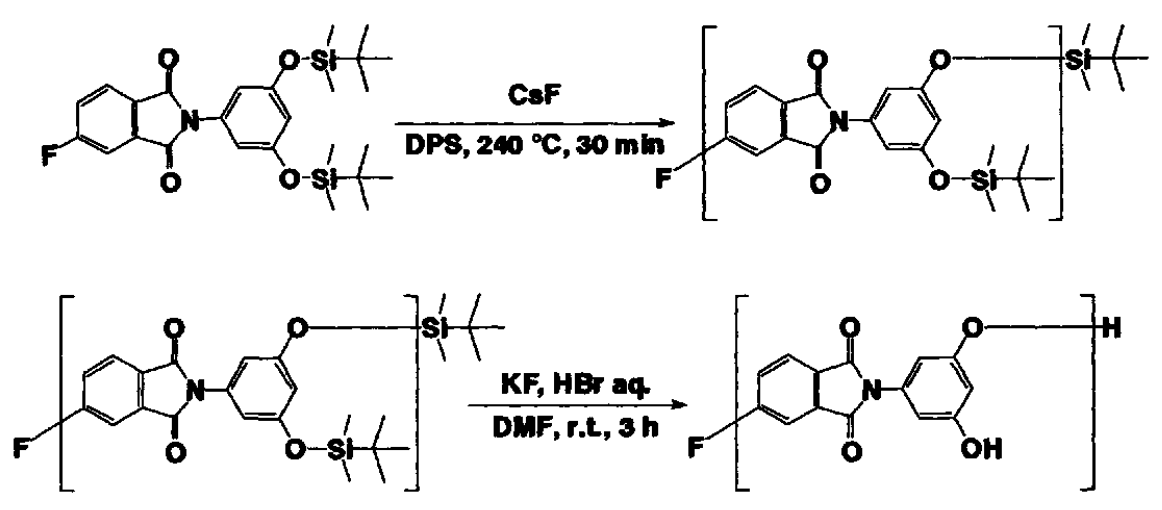

4

Scheme 2. Polymer Synthesis

\subsection{Monomer Synthesis.}

2.2.1. Synthesis of 3,5-dimethoxyphenyl-4-fluorophthalimide (1).

To a round-bottom flask was added $3.5 \mathrm{~g}$ (23.0 mmol) of 3,5-dimethoxyaniline, $23 \mathrm{ml}$ of glacial acetic acid, and $4.2 \mathrm{~g}(25.3 \mathrm{mmol})$ of 4fluorophthalic anhydride. The mixture was stirred at reflux for $4 \mathrm{~h}$. After cooling the reaction mixture, the product 1 was precipitated in water and isolated by filtration. The product was dried in vacuo at 100 ${ }^{\circ} \mathrm{C}$ overnight. The yield was $6.5 \mathrm{~g}(94 \%)$. mp: 165 ${ }^{\circ} \mathrm{C}$. IR $(\mathrm{KBr}): v\left(\mathrm{~cm}^{-1}\right)=1778,1720 \mathrm{~cm}^{-1},(\mathrm{C}=\mathrm{O}$, st), 1604, 1477 (benzene ring, st). ${ }^{1} \mathrm{H}-\mathrm{NMR}$ (300 $\left.\mathrm{MHz},\left(\mathrm{CD}_{3}\right)_{2} \mathrm{SO}\right) \delta(\mathrm{ppm})=3.76 \mathrm{ppm}\left(\mathrm{s},-\mathrm{OCH}_{3}\right.$, $6 \mathrm{H}), 6.58,6.63 \mathrm{ppm}(\mathrm{t}, \mathrm{d}, \mathrm{J}=2.1 \mathrm{~Hz}$, benzene $(-$ $\left.\mathrm{OCH}_{3}\right)_{2}, 3 \mathrm{H}$ ), $7.70 \mathrm{ppm}(\mathrm{dd}, \mathrm{J}=8.4,2.1 \mathrm{~Hz}$, benzene, $1 \mathrm{H}$ ), 7.80 (dd, J=7.2, $2.1 \mathrm{~Hz}$, benzene, $1 \mathrm{H}), 8.00 \mathrm{ppm}(\mathrm{dd}, \mathrm{J}=8.1,4.5 \mathrm{~Hz}$, benzene, $1 \mathrm{H}$ ).
2.2.2. Synthesis of 3,5-dihydroxyphenyl-4-fluorophthalimide (2).

A three-necked flask equipped with a nitrogen inlet, a dropping funnel was charged with $3.4 \mathrm{~g}$ (11.3 mmol) of compound 1 and $40 \mathrm{~mL}$ of dichloromethane. To this cooled solution $\left(-10^{\circ} \mathrm{C}\right)$, a solution of $6.3 \mathrm{ml}(66.1 \mathrm{mmol})$ of boron tribromide in dichloromethane $(5 \mathrm{~mL})$ was added dropwise under nitrogen. Then the resulting solution was stirred at room temperature for $8 \mathrm{~h}$ and poured into a water. The product was filtered off and dried in vacuo at $50{ }^{\circ} \mathrm{C}$. The yield was $1.9 \mathrm{~g}(64 \%)$. $\mathrm{mp}$ : $289{ }^{\circ} \mathrm{C}$. IR $(\mathrm{KBr}): v\left(\mathrm{~cm}^{-1}\right)=1770,1693 \mathrm{~cm}^{-1}$, $(\mathrm{C}=\mathrm{O}, \mathrm{st}), 1616,1484$ (benzene ring, st). ${ }^{1} \mathrm{H}-\mathrm{NMR}$ $\left(300 \mathrm{MHz},\left(\mathrm{CD}_{3}\right)_{2} \mathrm{SO}\right) \delta(\mathrm{ppm})=6.28 \mathrm{ppm}(\mathrm{s}$ benzene $\left.(-\mathrm{OH})_{2}, 3 \mathrm{H}\right), 7.70 \mathrm{ppm}(\mathrm{dd}, \mathrm{J}=8.4,2.1 \mathrm{~Hz}$, benzene, $1 \mathrm{H}$ ), 7.78 (dd, $\mathrm{J}=7.5,2.1 \mathrm{~Hz}$, benzene, 1H), $7.99 \mathrm{ppm}$ (dd, J = 8.1, 4.5 Hz, benzene, $1 \mathrm{H}$ ). 
2.2.3. Synthesis of 3,5-di-t-butyldimethyl silyloxyphenyl-4-fluorophthalimide (3).

Compound 3 was prepared by the reaction of 3,5-dihydroxyphenyl-4-fluorophthalimide and $t$ butyldimethylsilylchloride according to a reported procedure.[8] The product was purified by recrystallization from $n$-hexane. The yield was $72 \%$. mp: $168{ }^{\circ} \mathrm{C}$. IR $(\mathrm{KBr}): v\left(\mathrm{~cm}^{-1}\right)=1781$, $1720 \mathrm{~cm}^{-1},(\mathrm{C}=\mathrm{O}, \mathrm{st}), 1608,1484 \mathrm{~cm}^{-1}$, (benzene ring, st). ${ }^{1} \mathrm{H}-\mathrm{NMR}\left(300 \mathrm{MHz},\left(\mathrm{CD}_{3}\right)_{2} \mathrm{SO}\right) \delta(\mathrm{ppm})$ $=0.19 \mathrm{ppm}\left(\mathrm{s},\left(-\mathrm{CH}_{3}\right)_{2}, 6 \mathrm{H}\right), 6.58,6.63 \mathrm{ppm}(\mathrm{t}, \mathrm{d}, \mathrm{J}$ $=2.1 \mathrm{~Hz}$, benzene $\left.\left(-\mathrm{OCH}_{3}\right)_{2}, 12 \mathrm{H}\right), 0.93 \mathrm{ppm}(\mathrm{s}$, $\left.\left.\mathrm{CH}_{3}\right)_{3}, 18 \mathrm{H}\right), 6.34,6.62 \mathrm{ppm}(\mathrm{t}, \mathrm{d}, \mathrm{J}=2.1 \mathrm{~Hz}$, benzene(-OSi-) $\left.)_{2}, 3 \mathrm{H}\right), 7.70 \mathrm{ppm}(\mathrm{dd}, \mathrm{J}=8.4,2.4$ $\mathrm{Hz}$, benzene, $1 \mathrm{H}), 7.80 \mathrm{ppm}(\mathrm{dd}, \mathrm{J}=7.2,2.4 \mathrm{~Hz}$, benzene, $1 \mathrm{H}), 8.00 \mathrm{ppm}(\mathrm{dd}, \mathrm{J}=8.1,4.5 \mathrm{~Hz}$, benzene, $1 \mathrm{H}$ ).

\subsection{Synthesis of Hyperbranched Poly(ether-imide) (H-PEI).}

The polycondensation of monomer $3(2.4 \mathrm{~g}$ : $4.8 \mathrm{mmol}$ ) was carried out in diphenylsulfone $(9.6$ $\mathrm{g})$ in the presence of cesium fluoride $(0.4 \mathrm{~g})$ at $240{ }^{\circ} \mathrm{C}$ for $30 \mathrm{~min}$. The yield was $1.3 \mathrm{~g}$.

The deprotection of $t$-butyldimethylsilyl groups was achieved with $\mathrm{KF}(0.5 \mathrm{~g}, 8.8 \mathrm{mmol}) / \mathrm{HBr}$ $(48 \%, 0.2 \mathrm{~mL})$ in DMF $(6.6 \mathrm{~mL})$ under nitrogen for $2.5 \mathrm{~h}$.

The number-average molecular weight of the H-PEI was determined to be 24,000 (polydispersity 1.7) by gel permeation chromatography (GPC) (relative to Polystyrene Standard). IR ( $\mathrm{KBr}$ ): $v\left(\mathrm{~cm}^{-1}\right)=1778,1716 \mathrm{~cm}^{-1},(\mathrm{C}=\mathrm{O}, \mathrm{st}), 1604,1477$ (benzene ring, st), $1284 \mathrm{~cm}^{-1}$, (-C-O-C-).

\subsection{Dissolution Rate.}

H-PEI was dissolved at $25 \mathrm{wt} \%$ in dimethylacetamide (DMAc) to which was added 2,3,4-tris[1-oxo-2-diazonaphthoquinone-5-sulfonyl oxy]benzophenone (DSSB) (10-30 wt\% of H-PEI).

The $2 \mu \mathrm{m}$ thick films on the silicon wafer were prebaked at $80^{\circ} \mathrm{C}$ for $10 \mathrm{~min}$, exposed at $365 \mathrm{~nm}$ wavelength to the filtered super-high-pressure mercury lamp, and were heated at $100{ }^{\circ} \mathrm{C}$ for 20 min (post exposure baking). Imagewise exposure through a mask was carried out in a contactprinting mode.

\subsection{Photosensitivity.}

The $2 \mu \mathrm{m}$ thick H-PEI films containing $30 \mathrm{wt} \%$ of D5SB on silicon wafer were exposed through a filtered super-high-pressure mercury lamp, developed in $2.38 \mathrm{wt} \%$ tetramethylammonium hydroxide (TMAH) aqueous solution, and rinsed in water. The characteristic curve of the normalized film thickness against exposure energy was obtained.

\subsection{Measurements}

FTIR spectra were measured on a Horiba FT720 spectrophotometer. ${ }^{1} \mathrm{H}$ and ${ }^{13} \mathrm{C}$ NMR spectra were recorded on a BRUKER DPX-300 spectrometer. Thermal analyses were performed on a Seiko SSS5000 TG-DTA 220 thermal analyzer at a heating rate of $10^{\circ} \mathrm{C} / \mathrm{min}$ for thermogravimetry (TG) and a Seiko SSS5000 DSC220 at a heating rate of $20{ }^{\circ} \mathrm{C} / \mathrm{min}$ for differential scanning calorimetry (DSC) under nitrogen. Molecular weights were determined by a GPC was performed using TOSOH HLC-8120 apparatus (column, TSKgel $\mathrm{GMH}_{\mathrm{HR}}-\mathrm{M}$; standard, polystyrene; solvent, DMF containing $0.1 \mathrm{wt} \% \mathrm{LiBr} ; 40^{\circ} \mathrm{C}$ ). The film thickness was measured on a Dektak3 system (Veeco Insturuments Inc.).

\section{Results and Discussion}

It is very important to design a matrix poly(imide)s with functional groups to make a new alkaline-soluble PSPI system, and their low solubility is always a problem. Hyperbranched polymers have many functional groups on the terminal units. Furthermore, it is well-known that hyperbranched polymers possess a good solubility in organic solvents. We selected a hyperbranched poly (ether imide) (H-PEI), which has a high thermal stability and many phenol groups on the terminal units. 3, 5-Di-t-butyldimethylsilyl (tBDS) oxyphenyl-4-fluorophthalimide (3) as an $\mathrm{AB}_{2}$ monomer was prepared as shown in scheme 1 according to a reported procedure.[8] Polymerization of monomer 3 was carried out in diphenylsulfone in the presence of cesium fluoride at $240^{\circ} \mathrm{C}$ for $30 \mathrm{~min}$., giving a t-BDS-protected $\mathbf{H}$ PEI. Deprotection of t-BDS groups was achieved with $\mathrm{KF}-\mathrm{HBr}$ (Scheme 2). The polymer was identified as the corresponding H-PEI by infrared spectroscopy. The IR spectrum showed strong absorptions due to the imide carbonyl group at 1774 and $1716 \mathrm{~cm}^{-1}$. The characteristic absorptions of hydroxyl group and ether bond were observed at 3400-3000 and $1157 \mathrm{~cm}^{-1}$, respectively. The molecular weight of the polymer was determined by GPC. The chromatogram has a unimodal distribution, and indicated the $\mathrm{Mn}$ and $\mathrm{Mw}$ values of 24,000 and 42,000 , respectively, using polystyrene standard, and the ratio of $M w / M n$ of 


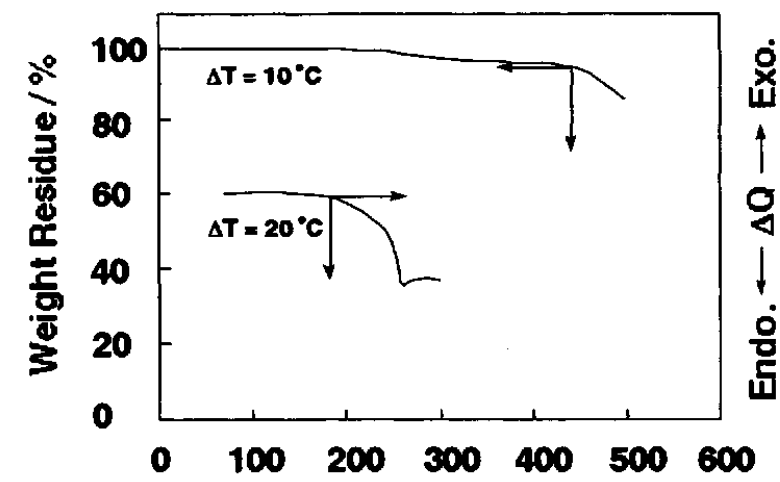

Temperature $/{ }^{\circ} \mathrm{C}$

Figure 1. TG and DSC curves of H-PEI in nitrogen.

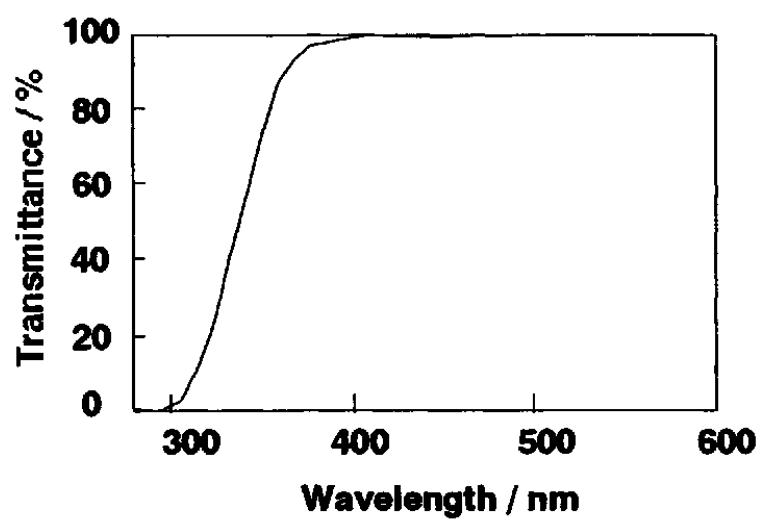

Figure 2. UV-vis. spectrum of H-PEI in DMF solution.

\section{7.}

The thermal stability of H-PEI was examined by thermogravimetric analysis (TGA) and differential scanning calorimetry (DSC). The polymer showed a $10 \%$ weight loss at $470{ }^{\circ} \mathrm{C}$ in nitrogen, and the glass transition temperature was observed at $250^{\circ} \mathrm{C}$ (Figure 1).

The transmission of UV-visible spectrum of $\mathbf{H}$ PEI in DMF solution is shown in Figure 2. It was found that an i-line $(365 \mathrm{~nm})$ irradiation was possible for this polymer because the transmittance of H-PEI at $365 \mathrm{~nm}$ was more than $90 \%$. We have chosen DSSB as a photoreactive DNQ compound. The changes of the UV-visible spectrum corresponding to the H-PEI film containing 30 wt \% of DSSB upon UV irradiation was shown in Figure 3. The absorption band at $320-440 \mathrm{~nm}$ of D5SB decreased with increasing UV irradiation. The resist consisting of H-PEI and D5SB as a

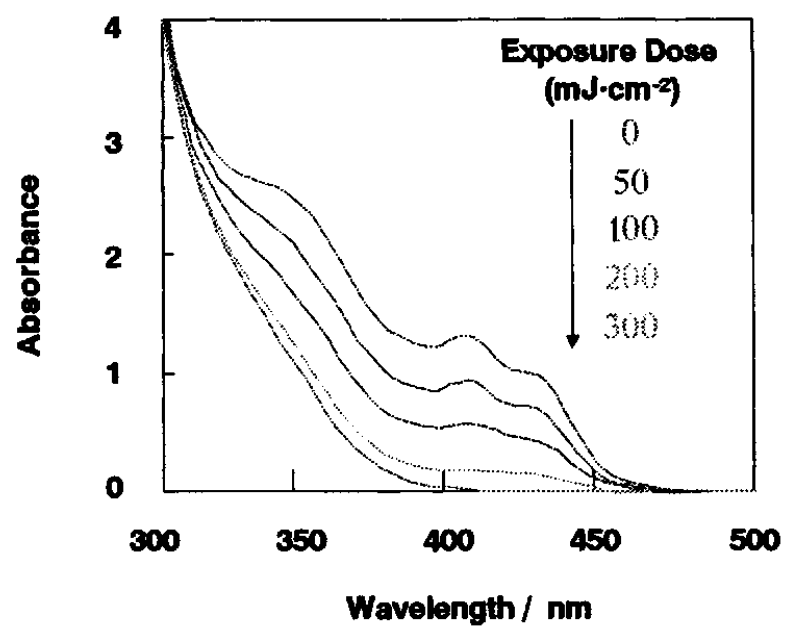

Figure 3. Change of UV-vis. spectra of D5SB (30 wt \% relative to H-PEI) in H-PEI film due to $365 \mathrm{~nm}$ light irradiation.

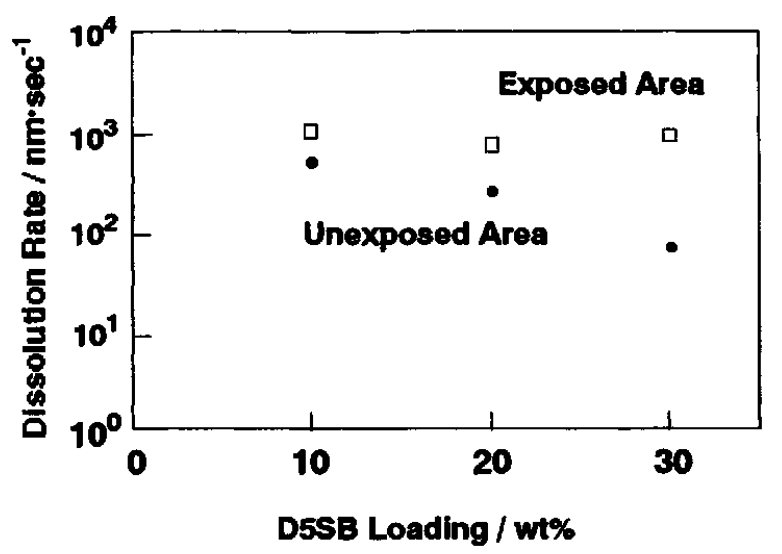

Figure 4. Effect of D5SB loading content on dissolution rate of H-PEI Film.

matrix and photoreactive compound, respectively, would be expected to show a high sensitivity toward i-line irradiation.

The effect of DSSB loading content on dissolution rate of H-PEI film was investigated to study dissolution behavior of the exposed and unexposed areas (Figure 4). The dissolution rate was estimated by measuring the film thickness after development for $22 \mathrm{sec}$, which was performed using 2.38 wt\% aqueous tetramethylammonium hydroxide (TMAH) solution as a developer.

It was found that a sufficient dissolution contrast was observed in the case of the H-PEI film containing $30 \mathrm{wt} \%$ D5SB. Furthermore, post exposure baking (PEB) of the film was performed to promote adhesion to silicon wafer. As a result, the most suitable PEB was at $100^{\circ} \mathrm{C}$ for $20 \mathrm{~min}$.

After these preliminary optimization studies involving irradiation, developing conditions and 


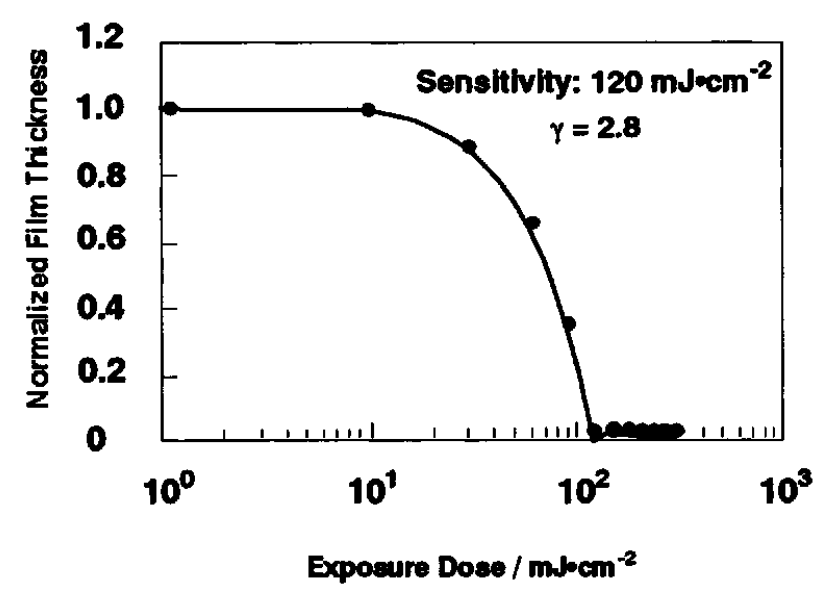

Figure 5. Exposure charasteric curve for the system of H-PEI and DSSB.

D5SB loading, a photosensitive polyimide system consisting of H-PEI and D5SB was prepared. The sensitivity curve for a $2 \mu \mathrm{m}$ thick film was consistent with the dissolution behavior studied above as shown in Figure 5. The sensitivity and contrast $(\gamma)$ were $120 \mathrm{~mJ} \cdot \mathrm{cm}^{-2}$ and 2.8 , respectively, after UV irradiation, PEB treatment at $100^{\circ} \mathrm{C}$ for $20 \mathrm{~min}$, followed by development with a $2.38 \mathrm{wt} \%$ TMAH aqueous solution. These findings indicated that this resist system had a relatively high sensitivity compared with the corresponding linear polyimide/DNQ system.[7]

\section{Conclusion}

A hyperbranched poly (ether imide) (H-PEI), was prepared by polycondensation of 3,5-di-tertbutyldimethylsilyloxyphenyl-4-fluorophthal-imide, followed by deprotection of di-tert-butyldimethylsilyl group. It was successfully applied as a new matrix of photosensitive polymer. H-PEI containing $30 \mathrm{wt} \%$ of diazonaphthoquinone DSSB functioned as a positive type alkaline developable photosensitive polymer. Its sensitivity and contrast were $120 \mathrm{~mJ} \cdot \mathrm{cm}^{-2}$ and 2.8 , respectively, upon 365 $\mathrm{nm}$ irraditation.

\section{Acknowledgements}

This study was financially supported by New Energy and Industrial Technology Development Organization (NEDO) for the project on Technology for Novel High Functional Materials (AIST).

\section{References}

1. Rubner, R.; Ahne, H.; Kunh, E. Photogr. Sci. Eng., 23 (1979) 303.

2. Omote, T. in "Polyimide" ed by Gosh, M. K.; Mittal, K. L. Marcel Dekker, Inc, New York (1996) $\mathrm{p}-121$.

3. Yoda, Y.; Morikawa, T.; Ando, T.; Fukami, A. $J$. Macromol. Sci. Chem. A-21 (1984) 1641.

4. Hayase, S.; Kihara, N.; Oyasato, N.; Matake, S.; Oba, M. J. Electrochem. Soc. (1991) 3625.

5. Omote, T.; Yamaoka, T.; Polym. Eng. Sci. 32 (1992) 1634.

6. Kubota, S.; Morikawa, T.; Ando, T.; Fukami, J.J. Macromol. Sci. Chem. A-24 (1987) 1407.

7. Nakayama T; Mochizuki A; Ueda M; Reac. Polym. 30 (1996) 109.

8. Thompson, D, S.; Markoski, J. L.; Moore, J. S.; Macromolecule 32 (1999) 4764. 